\title{
Impact of involvement of individual joint groups on subdimensions of functional ability scales in juvenile idiopathic arthritis S Meiorin*1, G Filocamo ${ }^{2}$, E Palmisani ${ }^{2}$, I Sala² ${ }^{2}$ S Magni Manzoni ${ }^{3}$, S Lanni ${ }^{3}$, S Viola ${ }^{2}$, A Buoncompagni ${ }^{2}$, A Pistorio ${ }^{2}$, N Ruperto ${ }^{1}$, A Martini $^{1}$ and
} A Ravelli ${ }^{1}$

Address: ${ }^{1}$ Hospital de Ninos Ricardo Gutierrez, Buenos Aires, Argentina, ${ }^{2}$ IRCCS G Gaslini, Genova, Italy and ${ }^{3}$ IRCCS Pol San Matteo, Pavia, Italy * Corresponding author

from 15th Paediatric Rheumatology European Society (PreS) Congress

London, UK. 14-17 September 2008

Published: 15 September 2008

Pediatric Rheumatology 2008, 6(SuppI I):PII6 doi:I0.I |86/I546-0096-6-SI-PII6

This abstract is available from: http://www.ped-rheum.com/content/6/SI/PII6

(c) 2008 Meiorin et al; licensee BioMed Central Ltd.

\section{Objective}

To investigate the influence of disease in individual joint groups on subdimensions of functional ability questionnaires in children with juvenile idiopathic arthritis (JIA).

\section{Methods}

206 patients who had the Childhood Health Assessment Questionnaire (C-HAQ) and the Juvenile Arthritis Functionality Scale (JAFS) completed simultaneously by a parent and received a detailed joint assessment were included. In each patient, joint involvement (defined as presence of swelling, pain on motion/tenderness and/or restricted motion) was classified in 3 topographic patterns: Pattern 1 (hip, knee, ankle, subtalar and foot joints); Pattern 2 (wrist and hand joints); Pattern 3 (elbow, shoulder, cervical spine and temporomandibular joints). Frequency of reported disability in each instrument subdimension was evaluated for each joint pattern, present either isolatedly or in mixed form.

\section{Results}

Among patients with Pattern 1, the JAFS revealed the greatest ability to capture and discriminate functional limitation, whereas impairment in the C-HAQ was more diluted across several subdimensions. Both C-HAQ and JAFS appeared to be less reliable in detecting functional impairment in the hand and wrist (Pattern 2) than in other body areas. Overall, the JAFS revealed a superior ability to discriminate the relative functional impact of impairment in individual joint groups among patients with mixed joint patterns.

\section{Conclusion}

In children with JIA, a functional measure focused to assess the function of individual joint groups (the JAFS) may detect with greater precision the functional impact of arthritis in specific body areas than does a standard questionnaire based on the assessment of activities of daily living (the C-HAQ). 